\title{
THERMOANALYSIS OF SOYBEAN OIL EXTRACTED BY TWO METHODS
}

Maria S. A. de Lima, Lucas A. Rocha, Eduardo F. Molina, Bruno L. Caetano, Liziane Marçal, César Mello, Katia J. Ciuffi, Paulo S. Calefi and Eduardo J. Nassar*

Universidade de Franca, Av. Dr. Armando Salles Oliveira, 201, 14404-600, Franca - SP, Brazil

Recebido em 29/1/07; aceito em 30/8/07; publicado na web em 26/2/08

\begin{abstract}
The thermal stability of vegetable oils is an important factor that affects their quality. In this study, we investigated the thermal stability of oil and lecithin extracted from soybeans by two distinct processes: mechanical extraction (pressing) and physical extraction (solvent). Thermal analysis was used to obtain information about different methodologies of extraction. The physically extracted products proved more stable than those extracted mechanically. Raman and UV-Vis techniques were applied to underpin the discussion of process differences.
\end{abstract}

Keywords: thermal analysis; vegetable oils; soybean oil.

\section{INTRODUCTION}

Vegetable matter usually contains $0.3-2.5 \%$ (dry weight) of phospholipids, while animal sources contain higher levels (eggs $14 \%$, brain $6 \%$, milk $2 \%$ ). Oilseeds, cereal germs, egg yolk, and fish are the richest sources of phospholipids ${ }^{1}$.

Although the soybean is one of the world's ancient agricultural products, interest in this plant was much heightened by the discovery of the edible oil it contains. Soybean oil is low in saturated fat and high in monounsaturated fat and polyunsaturated fat and in essential linoleic and linolenic fatty acids, which are necessary to human health. Oxidation of unsaturated lipids is one of the major causes of the development of off-flavor compounds and the reduction in nutritive value of food products ${ }^{2}$. Also, the antioxidants naturally present in soybean oil help to reduce damage by free radicals in the body. Soybeans have a very high phosphatides content, i.e., about $2 \%$, known as lecithin. Soy lecithin consists mainly of three types of phospholipids: phosphatidylcholine (PC), phosphatidylethanolamine (PE) and phosphatidylinositol (PI), which are commonly used as natural emulsifiers or stabilizers in a variety of foods.

Lecithin provides an excellent source of choline, which is essential to every living cell in the body and is one of the main components of cell membranes. Not only is dietary choline important for the synthesis of the phospholipids in cell membranes, but it is also necessary for methyl metabolism, cholinergic neurotransmission, transmembrane signaling and lipid-cholesterol transport and metabolism. Most of the choline in the body is present in phospholipids such as phosphatidylcholine and sphingomyelin ${ }^{3}$.

The stability and final quality of edible vegetable oils and their by-products are determined by the residual presence of certain minor compounds such as phospholipids, which provide good information about the proper oil processing and storage conditions ${ }^{4-6}$.

Classical extraction technologies are based on the use of an appropriate solvent to remove lipophilic compounds from inside plant tissues. The choice of a suitable sorbent in combination with sufficient mechanical agitation influences mass transport processes and the subsequent efficiency of the extraction ${ }^{7}$. Solvent extraction with n-hexane is a widely used approach for obtaining edible oil because of its low cost and its efficiency in terms of oil and solvent

*e-mail: ejnassar@unifran.br recovery ${ }^{7,8}$. Other methods for extracting edible oil are ultrasound and mechanical extraction (pressing).

In this work, we used thermal analysis to study the stability of soybean oil and lecithin extracted using or physical procedure (with hexane) and mechanically (by pressing) and Raman study interaction.

\section{EXPERIMENTAL}

Raw soybean oil, refined soybean oil and soybean lecithin obtained by solvent and press extraction were thermally analyzed using TA Q 600 SDT simultaneous TG/DTA/DSC, at heating rates of $10{ }^{\circ} \mathrm{C} \mathrm{min}-1$, in a nitrogen atmosphere and a temperature range of 25 to $650{ }^{\circ} \mathrm{C}$. The mass of the samples was 12 to $15 \mathrm{mg}$.

The Raman spectra were obtained using a Raman System II Ocean Optics spectroscope.

The phospholipids contained in soybean lecithin were examined by thin-layer chromatography, following the AOCS standard ${ }^{9}$. UVVis electron spectroscopy was used to determine the phospholipids in lecithin, based on the standard curve. The HP 8452 diode array was used to obtain the spectra.

The soybean oil was obtained by solvent and pressing ${ }^{10}$. The samples were analyzed as received from the supplier.

\section{RESULTS AND DISCUSSION}

Figure 1 shows the typical thermogravimetric curve for soybean oil extracted by solvent and pressing.

The samples displayed distinct thermal behaviors, with the oil obtained by the solvent technique showing greater thermal stability than that produced by pressing. The thermogravimetric curve revealed nonhomogeneity, probably due to the decomposition of oil in different steps, indicating the various components present in soybean oil. The oil extracted by pressing presented a slightly lower mass at temperatures above $500{ }^{\circ} \mathrm{C}$, unlike the oil obtained by solvent extraction, whose decomposition stopped at $485.6{ }^{\circ} \mathrm{C}$. Figure 2 presents the derivative of the thermogravimetric curve (DTG), which was used to identify the oil's initial, maximum and final decomposition temperature (Table 1).

The DTG curve presented a nonsymmetric peak, indicating that the decomposition occurred in several steps. The calculation of the entire area of the peak provided information about the amount of 


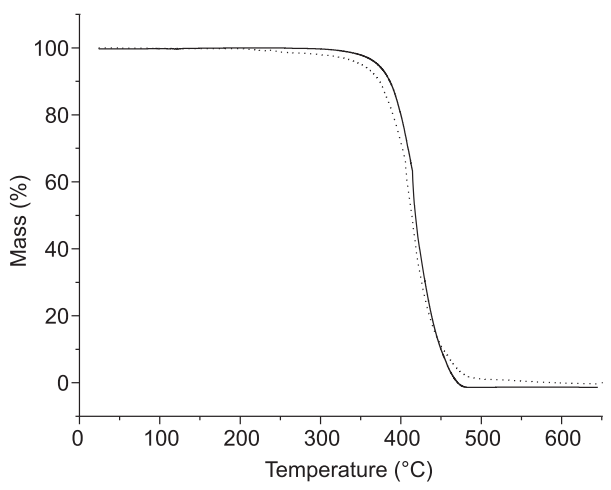

Figure 1. Thermogravimetric curve (TG) for soybean oil, (-) solvent and (...) press extraction at heating rates of $10^{\circ} \mathrm{C} \mathrm{min}^{-1}$, in a nitrogen atmosphere.

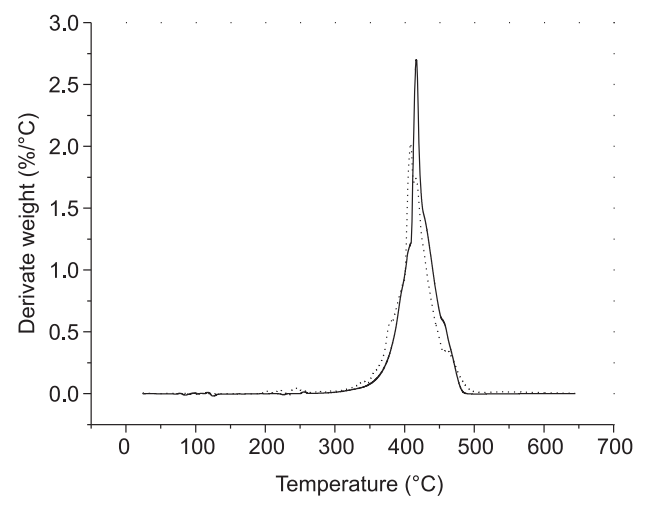

Figure 2. Derivative of the thermogravimetric curve (DTG) for soybean oil, (一) solvent and (․) press extraction.

Table 1. Integrated area (IA), initial temperature (IT), maximum temperature (MT) and final temperature (FT) of decomposition of soybean oil obtained chemically and mechanically

\begin{tabular}{lcccc}
\hline Soybean oil & $\mathrm{IT}\left({ }^{\circ} \mathrm{C}\right)$ & $\mathrm{MT}\left({ }^{\circ} \mathrm{C}\right)$ & $\mathrm{FT}\left({ }^{\circ} \mathrm{C}\right)$ & $\mathrm{IA}$ \\
\hline Solvent & 308.5 & 417.5 & 485.6 & 101.4 \\
Pressing & 286.4 & 411.5 & 509.5 & 97.1 \\
\hline
\end{tabular}

organic matter decomposition. The temperatures and area are shown in Table 1.

The maximum and final oil decomposition temperatures were very similar, but the initial decomposition temperature was $22.1^{\circ} \mathrm{C}$ higher for chemically extracted soybean oil (hexane). This temperature can be considered the temperature at which soybean oil remains stable. In this study, we found that the oil obtained by solvent presented greater stability than the oil obtained by pressing, possibly due to the presence of impurities in the mechanical extraction or decomposition of the oil's components. The areas of the peaks indicate that the product of solvent extraction presented more components than that of press extraction.

The differential thermoanalysis (DTA) revealed an endothermic peak corresponding to the decomposition of oil.

The soybean oil was refined to obtain degummed oil and lecithin. This process usually involves hydration of the oil, which produces oil-insoluble phospholipids that are easily removed ${ }^{11}$. The degummed oil and lecithin obtained by solvent and press extraction were studied by thermal analysis and Raman spectroscopy.

Figure 3 shows the typical thermogravimetric curve for degummed oil obtained by solvent press extraction.

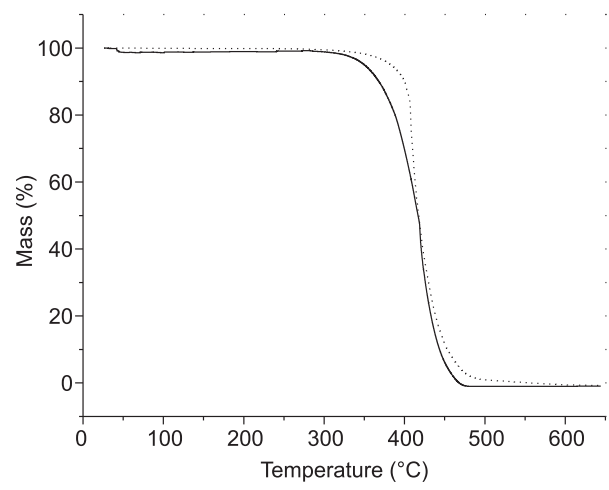

Figure 3. Thermogravimetric curve (TG) for degummed oil obtained by: (一) solvent and (.....) press extraction at heating rates of $10^{\circ} \mathrm{C} \mathrm{min}^{-1}$, in a nitrogen atmosphere

The TG curve for the samples showed an increase in the initial decomposition temperature, possibly due to the absence of lecithin, these temperature is presented in Table 2. The degummed oil obtained by the solvent and press method showed decomposition of the oil occurring in two steps, as confirmed by the derivative curve in Figure 4.

Table 2. Integrated area (IA), initial temperature (IT), maximum temperature (MT) and final temperature (FT) of decomposition of degummed soybean oil obtained chemically and mechanically.

\begin{tabular}{lcccc}
\hline Soybean oil & IT $\left({ }^{\circ} \mathrm{C}\right)$ & MT $\left({ }^{\circ} \mathrm{C}\right)$ & FT $\left({ }^{\circ} \mathrm{C}\right)$ & IA \\
\hline Solvent & 312.4 & 421.1 & 484.6 & 99.6 \\
Pressing & 328.5 & 409.8 & 502.3 & 99.7 \\
\hline
\end{tabular}

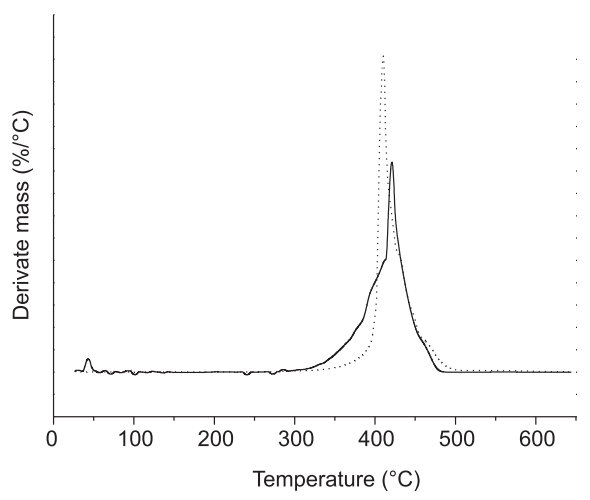

Figure 4. Derivative of the thermogravimetric curve (DTG) for degummed oil obtained by: (-) solvent and (‥) press extraction

The increase in the initial decomposition temperature indicates that lecithin (phospholipids) reduced the stability of soybean oil. The other temperatures presented little variation. The amount of decomposed material, in this case, was the same.

The thermogravimetric curve for lecithins showed a lower initial decomposition temperature than the oils and degummed oils. The degummed oil presented a higher initial temperature than soybean oil extracted by solvent and press, indicating that the lecithins reduced the oil's thermal stability. The lecithins obtained from pressextracted oil presented an area of 87.3 , while those obtained from solvent-extracted oil showed an area of 82.9, suggesting the former method produced a larger quantity of this substance. Table 3 lists these temperatures and areas.

Many authors have discussed the stability of soybean oil in 
Table 3. Integrated area (IA), initial temperature (IT), maximum temperature (MT) and final temperature (FT) of decomposition of lecithins deriving from solvent and press-extracted soybean oil

\begin{tabular}{lcccc}
\hline Soybean oil & IT $\left({ }^{\circ} \mathrm{C}\right)$ & MT $\left({ }^{\circ} \mathrm{C}\right)$ & FT $\left({ }^{\circ} \mathrm{C}\right)$ & IA \\
\hline Solvent & 165.0 & 360.7 & 512.9 & 82.9 \\
Press & 149.1 & 371.9 & 515.5 & 87.3 \\
\hline
\end{tabular}

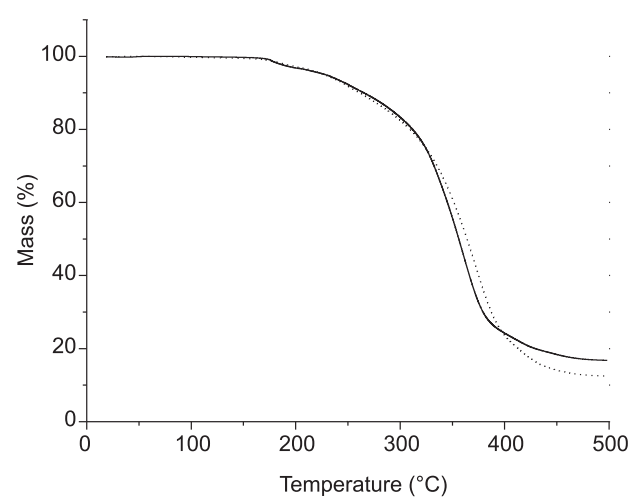

Figure 5. Thermogravimetric curve (TG) for lecithin obtained by extraction of soybean oil by: (-) solvent and (…) press extraction at heating rates of $10^{\circ} \mathrm{C} \mathrm{min}{ }^{-1}$, in a nitrogen atmosphere

relation to the quantity of phospholipids (lecithins) ${ }^{1-4}$. Gennero et $a l^{12}$. stated that lipid autoxidation contributes significantly to the deterioration and reduction of the shelf life of many products due to a free-radical chain reaction, and that some of the effects of lipid oxidation are changes in color, texture, odor, and flavor. When triglycerides and phospholipids were removed, a remarkable difference in aroma was noted, indicating that structural phospholipids play a significant role in meat aroma specificity. Phospholipids contribute through lipid-derived odorants generated by thermally induced lipid oxidation ${ }^{1,2,4}$. Although lecithins interfere in the stability of oil, they nonetheless provide a functional benefit, since they are an excellent source of choline, which is essential to every living cell in the body and is one of the main components of cell membranes ${ }^{3}$.

The Raman spectra presented molecular vibrations in the infrared electromagnetic region, and we observed an interaction between the oil components and the solvent. Hexane is a non-polar solvent, which is an important factor for extracting large quantities of non-polar components from oil, such as unsaturated fatty acids. The interaction can be observed by shift of the wave number of the peak.

The Raman spectra presented peaks at 1591 and $1793 \mathrm{~cm}^{-1}$, which were ascribed $\mathrm{C}=\mathrm{C}$ in solvent-extracted soybean oil. The press-extracted oil showed peaks at 1596 and $1797 \mathrm{~cm}^{-1}$, also ascribed $\mathrm{C}=\mathrm{C}$. This difference in wavenumber values may be due to the interaction between the solvent and components of oil molecules, which results in a greater quantity of fatty acids extracted chemically.

The Raman spectra presented vibrational and stretching modes characteristic of phospholipids. The band at $1098 \mathrm{~cm}^{-1}$ was ascribed to $v(\mathrm{C}-\mathrm{C})$, the band at $1292 \mathrm{~cm}^{-1}$ was attributed to the $\delta\left(=\mathrm{CH}_{2}\right)$ of the phospholipids, and the one at $1445 \mathrm{~cm}^{-1}$ to the $\delta\left(\mathrm{CH}_{2}\right)$ of the lipids (Figure 6).

Table 4 shows the concentration of phospholipids in lecithins, which was determined following the AOCS standard 9

The quantity of phospholipids differed according to the extraction method, solvent and pressing. Of the five components extracted from soybean oil, only the PA component was absent from the pressextracted oil, while the other four were present, but in different quantities. PC, a major component of lecithin and important in the diet $^{3}$, was obtained more efficiently by solvent extraction.

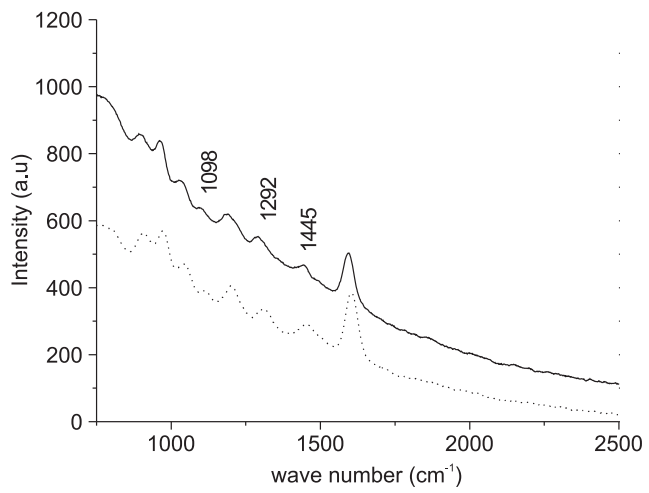

Figure 6. Raman spectra for soybean oil, (-) solvent and ('..) press extraction

Table 4. Lecithins obtained by the AOCS method: phosphatidylcholine (PC), phosphatidylethanolamine (PE), phosphatidylinositol (PI), phosphatidic acid (PA) and lisophosphatidylcoline (LPC)

\begin{tabular}{lcc}
\hline phospholipids & $\begin{array}{c}\text { Lecithins by } \\
\text { solvent } \\
(\mu \mathrm{g} / 500 \mathrm{mg})\end{array}$ & $\begin{array}{c}\text { Lecithins by } \\
\text { pressing } \\
(\mu \mathrm{g} / 500 \mathrm{mg})\end{array}$ \\
\hline LPC & 23.13 & 27.25 \\
PC & 24.85 & 5.42 \\
PI & 5.21 & 19.68 \\
PE & 9.81 & 18.84 \\
PA & 8.46 & - \\
Total & 61.65 & 71.19 \\
\hline
\end{tabular}

\section{CONCLUSIONS}

The findings of this study have implications for edible soybean oil. The two extraction methods exerted little difference on the thermal stability, due to the difference in the oil compositions, as observed in the percentage of phospholipids in the lecithin. However, the method of extraction can affect the composition of lecithin.

\section{ACKNOWLEDGEMENTS}

The authors gratefully acknowledge the financial support of FAPESP, CNPq and CAPES (Brazil).

\section{REFERENCES}

1. Lin, J.; Blank, I.; J. Agric. Food Chem. 2003, 51, 4364.

2. van Aardt, M.; Ducan, S. E.; Long, T. E.; O’Keefe, S. F.; Marcy, J. E.; Sims, S. R.; J. Agric. Food Chem. 2004, 52, 587.

3. Zeisel, S. H.; J. Am. Coll. Nutt. 2000, 19, 528S.

4. Zamora, R.; Olmo, C.; Navarro, J. L.; Hidalgo, F. J.; J. Agric. Food Chem. 2004, 52, 4166.

5. Smith, S. A.; King, R. E.; Min, D. B.; Food Chem. 2007, 102, 1208.

6. Biswas, A.; Adhvaryu, A.; Stevenson, D. G.; Sharma, B. K.; Willet, J. L.; Erhan, S. Z.; Industrial Crops and Products 2007, 25, 1.

7. Li, H.; Pordesimo, L.; Weiss, J.; Food Res. Int. 2004, 37, 731.

8. Gaur, R.; Sharma, A.; Khare, S. K.; Gupta, M. N.; Bioresour. Technol. 2007, 98, 696.

9. AOCS; Recommended Practice Ja 7-86, Sampling and Anaysis of Lecithin, Phospholipids in Lecithin Concentrates by Thin-Layer Chromatography, Official Methods and Recommended Practices of the AOCS; $5^{\text {th }}$ ed. $-2^{\text {nd }}$ printing.

10. de Lima, M. S. A.; Dissertação de Mestrado, Universidade de Franca, Brasil, 2005.

11. Moreto, E.; Fett, R.; Tecnologia de Óleos e Gorduras Vegetais na Indústria de Alimentos, Livraria Varela: ??? 1998, cap. I.

12. Gennaro, L.; Bocca, A. P.; Modesti, D.; Masella, R.; Coni, E.; J. Agric. Food Chem. 1998, 46, 4465. 